\title{
Lean Six Sigma to reduce blood wastage
}

T he Chinese philosopher Lao-tzu once said that the journey of a thousand miles begins with a single step. If that is true, then some first steps, either because of their direction or their size, are more significant than others. "Blood wastage reduction using Lean Sigma methodology," by Heitmiller and colleagues ${ }^{1}$ in this issue of TRANSFUSION represents this journal's first publication of Lean Six Sigma initiatives in transfusion medicine- and that is a big and well-directed first step.

Process engineering tools and philosophies, extending from the time-motion studies of Frank and Lillian Gilbreth $^{2}$ and the production lines of Henry Ford in the early 1900s, were progressively refined by the US Military, W. Edwards Deming, ${ }^{3}$ and industrialists in Japan after World War II and have been slowly winding their way into health care since the early 1990s. These initiatives have taken the industrial engineering strategies refined in the Toyota Production System (TPS) and applied them to health care practices in efforts to reduce waste, errors, and costs, while at the same time improving customer and employee satisfaction, safety, and quality.

To understand fully the foundations of the TPS requires an understanding of the complex interplay of work, workers, layout of the workplace, materials, products, tools, processes, the environment, change management, training, communication, suppliers, and customers just for starters. With the help of Liker, ${ }^{4}$ Rother and Shook, ${ }^{5}$ and other refiners of this complex information set, the patterns that define the critical elements of successful implementations of the TPS in health care emerge:

1. Define a critical metric.

2. Seek to understand the processes and variables that impact that metric.

3. Employ strategies to systematically improve the metric by modifying or eliminating the variables.

4. Define, validate, implement, and monitor best practices.

5. Continuously review and experiment with ways to improve.

6. Integrate the knowledge gained through experiences into other parts or processes of the system.

This sequence is bound to be familiar to health care practitioners because it is the basis of the scientific method employed in our schooling and in our research

TRANSFUSION 2010;50:1860-1861. laboratories. The scientific method, at its foundation, teaches a systematized approach to strategic thinking to solve problems or unknowns. In that sense, it is identical to the TPS. One would predict therefore that the implementation of the TPS in our health care environments should be a short leap. Still, the first steps toward any new journey take courage and commitment. Heitmiller's team displayed both admirably.

\section{Courage}

In a field as significant and essential as health care, we pride ourselves on our commitment to high-quality work and care for our patients. There is no one working in health care today that begins their workday espousing "Gee, how can I screw up today?" Our workers and our leaders are among the finest around, yet we know that mistakes do occur, waste happens, and costs are not as low as they could be. It takes tremendous courage to stand up and declare, "Parts of what we are doing today are defective. They may be wrong, ineffective, inefficient, or too costly." It is challenging to make such declarations because we know that the great majority of time the care that we provide is outstanding and the people working in our systems are sincerely dedicated to high-quality care, service, and cost containment. Still, we must recognize that if we have good people working in bad processes, the bad processes will triumph every time. We must have the courage to stand up and say, "Yes, we have good people but some of our processes are broken!" By monitoring a critical metric, wasted red blood cell (RBC) units, Heitmiller and coworkers revealed that they had a broken process at their institution-their wastage was excessive according to their high standards. They surfaced this as a problem, not only at their institution but also for the public to see in this month's publication-and that takes courage! A key operational and philosophical tenet of the TPS is to surface rather than conceal defects and bad processes-expose them to the light of day and to public scrutiny and even celebrate the fact that they were identified (for they represent opportunities to improve). Then ... set about to systematically abolish them!

\section{Commitment}

Once RBC wastage was identified as a problem, a multidisciplinary team assembled and dedicated themselves to make improvements. Seeking a new way of thinking, they committed their time and energy to learn and apply key 
components of the TPS, Lean Six Sigma (LSS). LSS is a combination of two distinct strategies (Lean and Six Sigma) that apply some overlapping tools and philosophies to effect improvements. Lean is a disciplined approach to eliminating wastes in processes (transportation, inventory, motion, talent, waiting, overproduction, overprocessing, and defects). Six Sigma is a disciplined application of the scientific method to eliminate errors in processes (define, measure, analyze, improve, and control). Both Lean and Six Sigma rely on process review and improvement in a prescribed fashion (plan-do-checkact). Whether using a consultant, teacher, or coach to guide task-focused team learning, or undertaking classroom training with the hope of applying Lean Six Sigma more broadly, it takes a commitment of time (money!), energy, and emotion from workers who are frequently stressed by one or several of these same resources. To enable workers to undertake LSS learning in this way requires the courage and support (money!) of leadership as well as a commitment to deliver a better future.

For initial implementations of LSS, successful outcomes are critical if long-term acceptance is to be achieved. Positive outcomes not only validate LSS as a strategy but also stimulate learning and applications of LSS in other settings. In Heitmiller's team's work, the outcomes are dramatic. RBC wastage decreased by 61 percent, resulting in a savings of $\$ 800,000-$ a gain that only represents the financial savings to the institution (money!); tangible savings were also made by reclaiming 4300 RBC units to treat other patients. Less easily measured-but potentially more profound-will be the value of LSS knowledge as it is applied by team members to other health care processes. Certainly the investment in training personnel will return to this institution again and again through the years.

How long will it take to learn what LSS can teach to improve our healthcare practices? Toyota has been refining its methods for more than 50 years now and can finally realize rapid cycle improvements from day to day or shift to shift. The United Kingdom leads the United States in forwarding LSS as a national health care standard. ${ }^{6}$ I am frustrated and dismayed when I see reports of LSS projects taking years to effect improvements that could be made in weeks or even days. The improvements described herein took years to implement and that is too long to wait when patient care, rising costs, and precious resources lie in the balance. We must find ways to apply the strategies of process engineering in our health care environments more rapidly and organizations are now emerging to do just that; the Institute for Industrial Engineers Society for Health Systems and the American Society for Quality are just two organizations looking to bridge what engineering has to offer with what health care requires. I encourage health care leaders to support these initiatives and bring process engineering-and process engineers- increasingly to the forefront of health care education and process improvement.

Finally, one cannot talk about the TPS without acknowledging the recent recalls of Toyota's cars for acceleration and safety concerns. ${ }^{7}$ In health care's application of LSS, our target-rich environment needs to focus efforts on the QSEAS of health care-quality, safety, efficiency, appropriate utilization of resources, and service. These targets are not equivalent, however. Of these, safety, both employee and patient safety, is paramount; no process improvement should be implemented if safety is in turn diminished. Let the recent recalls at Toyota serve not to tarnish the potential of LSS but instead as a clear reminder that safety is our ultimate priority. The TPS is about continuous improvement achieved through continuous experimentation and learning. We must learn from Toyota's successes-and learn even more from their failures. As we increasingly learn to apply LSS in our environments, I encourage you to share your experiences-both successes and failures-in the pages of TRANSFUSION in the years to come.

\section{CONFLICT OF INTEREST}

None.

\author{
Steven H. Mandell, MD \\ e-mail:smandell@umich.edu \\ Department of Pathology \\ The University of Michigan Medical School \\ Ann Arbor, MI
}

\section{REFERENCES}

1. Heitmiller ES, Hill RB, Marshall CE, Parsons BJ, Berkow LC, Barrasso CA, Zink EK, Ness PM. Blood wastage reduction using Lean Sigma methodology. Transfusion 2010;50:188796.

2. Gilbreth F, Gilbreth L. Applied motion study. 2th ed. New York, NY: The MacMillan Co.; 1920.

3. Deming WE. Out of the crisis. Cambridge, MA: Massachusetts Institute of Technology; 1982.

4. Liker J. The Toyota way: 14 management principles from the world's greatest manufacturer. New York, NY: McGrawHill; 2004.

5. Rother M, Shook J. Learning to see: value stream mapping to add value and eliminate muda. Cambridge, MA: Lean Enterprise Institute, Inc.; 2003.

6. Department of Health Pathology Service Improvement Team. Modernising pathology services toolkit—a practical guide to service improvement. Available from: http:// www.pathologyimprovement.nhs.uk/documents/key_ documents/Pathology_Guide05.pdf. 26 September 2005

7. Various contributors. http://en.wikipedia.org/wiki/ 2009\%E2\%80\%932010_Toyota_vehicle_recalls. July 15, 2010. 